\title{
MORAL DEVIATION IN YOUNG PEOPLE OF BANGLADESH
}

\author{
Rowshan Ara Ph.D'1 Tanha Mahjabeen²
}

1. Professor, Department of Philosophy, University of Dhaka,

2. Ph.D. Student, Curtin University of Technology, Perth, Western Australia

\begin{abstract}
Youths of Bangladesh (18-35) constitute one-third of the total population. In this article, young people imply both adolescents and youth. There are 28 million adolescent populations in Bangladesh. Approximately there are sixty million young people in Bangladesh The vast majority of them are illiterate, and handicapped with severe poverty. Because of lack of family control, proper education, poverty, unemployment and peer pressure a significant portion of them are deviated from the norm of the society. In this paper four issues of moral deviation- eve teasing, drug and substance abuse, juvenile delinquency and access to pornography will be discussed.
\end{abstract}

Juvenile Delinquency: Juvenile delinquency is a major concern in Bangladesh where the number of youth involved in anti-social activities appears to be on the rise. With the advancement of industrialization and urbanization, juvenile delinquency is gradually rearing its ugly head and making the problem more acute day by day. The new manifestations of juvenile delinquency take such characteristic forms as gang activities, purposeless offences, acts of vandalism, joy-riding, terrorism, eve-teasing and the like which can be serious from the point of public order without necessarily being an indication of serious anti-social behavior. Brought up in an unwholesome environment they develop wrong norms and values and it becomes difficult to bring them back to the right path. Studies on criminal behavior has shown that a good percentage of adult criminal committed first offence in their childhood long before their first conviction.

A study titled "Under-Aged Prison Inmates in Bangladesh: A Sample Situation of Youthful Offenders in Greater Dhaka", (ActionAid, November 2008) found that the dominant agegroup of the inmates having committed crime is between 12 and $<16$ years $(64.58 \%)$, and it was found that $31.25 \%$ did not attend school. In this area, there is an improvement over the study conducted during the year 2003 , when $41 \%$ were found to have not attended school at all. Out of whole of the inmate population, the representation of the Dhaka Metropolitan area was more than $61 \%$, and Mirpur Police Station area appears to be the first among the Police Station to have contributed largely to the sample within the city. Among the 5 districts, Narshingdi has the highest numbers. The important charges/complaints against the inmates were theft $(22.92 \%)$, murder $(18.05 \%)$ as against $15.57 \%$ during the year 2003 , drug related offence (13.19\%) and possession of illegal arms (10.14\%) as against $27.33 \%$ during the year 2003. Situation regarding other offences remained almost static. The inmates of Prison and Correctional Homes have been staying for a period of about 3 months (almost $50 \%$ ).

The inmates of Jail and Kishore Unnoyon Kendra (KUK) mostly come of poor family. Due to poverty they have to face they are habituated in different adventures. Due to struggle for existence they are fond to be adventurous. About 39\% admitted that they had adventurous incidents in their life. They gave 27 kinds of adventurous activities. Different information comes out from them and its degree was also different. Those who disclosed about their adventurous activities, like association with friends, free movement and also want to work 
outside family disciplines. They become easily involved with crime in absence of family governance and bad companion. They are organized adventures whereas their works are such as :- rescue a child from fire, coming to the town alone, elopement, stealing of fruits from garden, inscribing names by cutting own skin, climbing the hills, salvaging from drowning, catching and charming snakes, weight lifting, breaking hands by falling from tree, crossing river, rape, carrying arms, hijacking, throwing stones to police etc. It seems the petty crimes from childhood lead them to bigger crimes.

Eve-Teasing by the Young People: Constant eve teasing by way ward naughty young people become an issue of grave concern to the society throughout the country. Eve-teasing has been identified as the beginning of violence against women. According to the press reports during 2001 to 2006, a five-year period, ten girls committed suicide owing to harassments by local young hoodlums, goons, and terrorists. Eight of them were 9-16 years, the rest two were 21/22 years old. The most tragic incidence happened when Trisha, a 9-year old girl, jumped into a pond and drowned as she was chased by three local goons on her way back home from school.

Another fatal incidence can prove the unsafe and insecure condition of the female adolescents. Rumana Parveen (Teethi), (age-13) of Savar Girl's high School committed suicide because of constant verbal and physical abuse by some hoodlums of her locality. Rumi, Trisha, Shimi, Sopura and some other girls also have the same fate because of constant eve-teasing by some derailed young people (Prothom Alo, September 20, 2006).

Despite enactment of the Suppression of Violence against Women and Children Act 2000 (Amended in 2003) the country has made very little progress particularly with respect to protecting the adolescent girls outside home. A research conducted on a very large sample of 203077 households covering various rural and urban areas of the country reveals that about 6.0 per cent of the dropout children were such cases that their parents had to stop sending them to school because they felt "insecure" (Mia and Hassan 2008). While law and law enforcement is inadequate to address the issue, social mobilization and protest against such heinous atrocities is so far absent. NGO's campaign against violence against women and adolescent girls has had only small effect given their limited scale of operation and coverage. The government machineries including the state run media have not been sufficiently effective in mobilizing all social agencies and the law enforcement system has not had its proper application to stop gendered violence by the deviated young people.

Recently the girl student of Sunamganj and Fulpur of Mymensingh abstain from attending class as a protest against the torture of the eve teasers (Prothom Alo, July 7, 2009). The people of Sunamganj caught hold of an eve-teaser who manhandled a school girl and handed him over to the police. These type of eve teasers always block the road of their school going girls and disturb them by abusing words and obscene gesture. Young people need proper guidance, counseling, develop livelihood skill so that they do not waste their time and strength by teasing the girls. If we can not save the girls from these eve teasers and ensure their security how can we expect a civilized society?

Drug and Substance Abuse: Drug abuse is a gruesome menace in the society today-with grave biological, social, economic and security implications on the individual, family, community and the country. The alarming speed, with which the drug scourge has ravaged the whole country, particularly over the last two decades, has brought the threat of the menace to every door step.

Adolescents' and youth's drug use fits a "Cultural deviance model of behavior". For young people reliance of drugs may reflect emotional disturbance of varying degrees of severity 
and an inability to cope with the demands of living or to find a meaningful personal identity. These may be profound disturbance in family relationship or disadvantaged adolescents facing a future without hope and confronted with economic, social discrimination with inhuman living conditions, often with untreated physical needs and a breakdown in their family social relationship may give up a sense of ego-identity and try to escape in the oblivion of drugs. Drug abuse, criminal and other antisocial behavior has been attributed to peer group influence and pressure. Juvenile delinquency is very much co-related with drug addiction.

The real scenario of drug abuse is indeed a frustrating one. According to the statement of Department of Narcotic Control, About 100,000 people, including 30,000 women and children, are involved in illegal drug trade in Bangladesh. Drug dependents spend at least 460 million $^{3}$ taka (about 6.57 million U.S. dollars) on narcotics every day. There was no specific government data on the number of drug addicts or drug use in the country.

According to the $\mathrm{FHI}$ in 2004 there were some 4.6 million drug addicts in the country. Heroin is the most widely abused hard drug and around 75 percent of the dependent are 15-30 years old. A rapid situation assessment on drug and substance use was conducted by UNICEF in 2008. The study is focused in selected divisional cities and convergence districts of Bangladesh namely Dhaka and Gazipur in Dhaka division, Chittagong and Cox's Bazar in Chittagong division, Khulna and Kushtia in Khulna Division, Barisal and Barguna in Barisal Division, Sylhet and Moulavi Bazar in Sylhet Division and Rajshahi and Chapainawabganj in Rajshahi Division. Findings from the rapid assessment revealed that the average age of the drug users is 16 years, with $42 \%$ of them being below the age of fifteen years. $17 \%$ of the injecting drug users have shared syringe/ needles. The main initiation age 11 years to 15 years, during this age $79 \%$ of the children had initiation to sex. $82 \%$ of the girls had ever sold sex for buying drugs.

The vulnerability of both the boys and girls is very obvious as $68 \%$ of the boys had sex with sex workers in one or more of their last three sexual intercourses, and $59 \%$ of the girls had sex with their clients in the same number of sex occasions. Majority $(59 \%)$ of the young people faced harassment due to taking drugs.

According to the assessment, conducted in Dhaka city from April 2006 to June 2006 (UNICEF, 2008). The study team found out total 229 drug users spot, among them 21 of the injecting drug users spot, 77 of the heroin smokers spot and other 131 spot where Drug users take other drugs. Other types of drugs include Ganga, sleeping pill, Glue inhale, Phensidyle, etc. The study shows the estimated size of high risk population in terms of 75 to 90 injecting drug users, 565 to 775 heroin smokers and around 2075 to 2760 other types of the drug users (Except cigarette smokers). 71 percent of children and adolescents coming in contact with drugs through peer pressure. Further, the more drugs adolescents use, the more likely they are to have friends who use not only those drugs but other drugs as well. Though there are some programs for young and adolescent children, drug use prevention or harm reduction focused interventions are not seen with national commitment. In this regard, policy initiative, implementation structure and capacity are lacking. Govt. of Bangladesh set up a specialized drug addiction treatment hospital at Tejgaon, Dhaka under the administrative control of DNC. Drug addiction treatment programs in Bangladesh are limited within the process of detoxification. Rest of the programs is not supported by appropriate after care, follow up motivation, counseling, skill development training, rehabilitation and social re-integration program.

A country wise study is needed to assess the situation and combat this rehabilitation of the addicts and introduce preventive education for the adolescents on an urgent basis. In order to combat this dangerous situation Community leaders, parents and teenager counselors who are willing to serve as "preventive agent" should be involved in this process. 
Access of Young People to Pornography: Most of the adolescents especially the adolescent boys use to watch porno film on Compact Disc (CD). The pirated copies of these CDs are very cheap and available throughout the country. In all Metropolitan Cities the roadside stores sell these CDs and most of the sellers are adolescent boys. When someone visits these stores the seller talks with local sign languages to inform that he has those porno films. In interviews with different CD sellers it is found that large numbers of consumers are both school going and non-going adolescents. They exchange CDs, one with others among the friends. Many of these students preserve porno MP4 and Porno images in their cell phone and enjoy these in a group. Sometimes they send these to their friends and other girls through SMS and make them embarrassed. Uncontrolled access to Internet and satellite TV channels is promoting this trend among the adolescent population.

Root Causes of Moral Deviation the following:

Lack of proper education, drop out.

Unemployment and poverty.

Lack of family control.

Urbanization and slummization.

Lack of provision for meaningful utilization of leisure time.

Broken and troublesome family.

Ineffective role of law enforcing agency.

Influence of alien culture and media exposure to obscene film and culture of violence.

$>$ Peer pressure.

$>$ Political exploitation of young people.

\section{Suggested Recommendation:}

- $\quad$ To strengthen interpersonal communication and conflict resolution in the families by increasing moral values and increase family bondage.

- $\quad$ To include the drug use prevention information including negative consequences of drug use in the formal education text book starting from class four to ten

- $\quad$ Easy supply and availability of drugs should be stopped and exemplary punishment to the drug traffickers should be given.

Promotion of moral values in the family.

- $\quad$ Provide marketable entrepreneurships for the dropout youths.

- $\quad$ Ensure life-relevant education curriculum at secondary level, and widen the provisions for well-managed technical-vocational education appropriate for employment market.

- $\quad$ Life skill education should be incorporated with formal education. Particularly on adolescent relevant issues like coping with stress, coping emotions, Self-awareness building, Empathy etc. that would ensure smooth transition of adolescents to adulthood and enhance capability to play effective role in family, community and social life.

- $\quad$ Family life education should be included in the syllabus of formal and non formal education.

Values are of vital concern for youth. Now there is no moral radar to guide young people. In midst of rapid social change the difference between right and wrong has been blurred. Adult people are formulating their own code of conduct in order to fulfill their selfish motive and demands. Unless the socioeconomic problems of the young people can be resolved, until some better match can be found between vocational opportunities and the needs, talents, skills and values of young people, both society and youths are likely to be in serious trouble. 
Responsibility of the parents, community leaders, teachers and the NGO and GO are of utmost importance to save the future citizens from the moral erosion

Therefore, healthy environment must be created in which young people will find encouragement to achieve real heroism to eradicate evil and corruption from the society. The youth should not be identified as a symbol of terrorism, violence, indiscipline and destruction. They were the hope of yesterday, joy of today and the guarantee of a better tomorrow. 